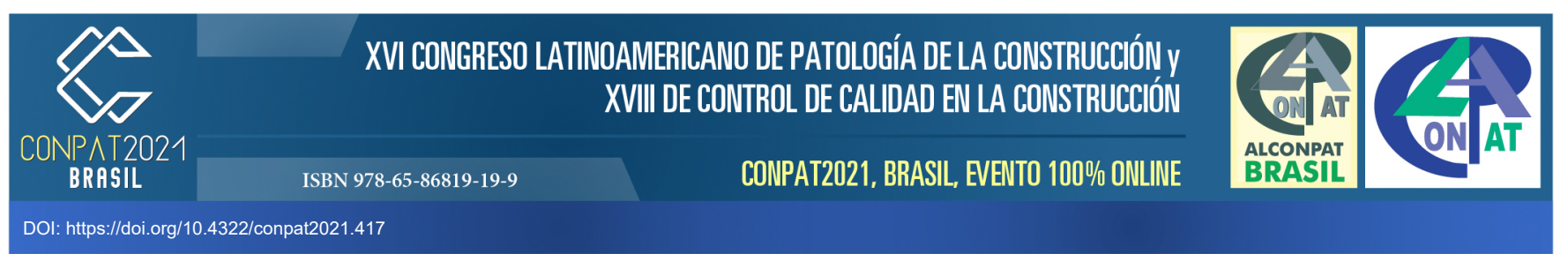

\title{
Análise do desempenho térmico dos sistemas de vedações vertical confeccionados com alvenaria de rochas
}

\author{
Helena. Rodrigues Leite ${ }^{1 *}$, Roberto. Christ ${ }^{2,}$ Fernanda Pacheco ${ }^{3}$, Hinoel Zamis Ehrenbring ${ }^{4}$, \\ Maria Fernanda de Oliveira ${ }^{5}$ \\ *e-mail: helenarleite93@gmail.com
}

\footnotetext{
${ }^{1}$ Especialista em Engenharia Civil, pelo Curso de Especialização em Patologia e Desempenho das Construções da Universidade do Vale do Rio dos Sinos - UNISINOS, Porto Alegre/RS, Brasil.

${ }^{2}$ Doutor em Engenharia Civil, Professor e Pesquisador da Universidade do Vale do Rio dos Sinos - UNISINOS- itt Performance, São Leopoldo/RS, Brasil.

${ }^{3}$ Doutora em Engenharia Civil, Professora e Pesquisadora da Universidade do Vale do Rio dos Sinos - UNISINOSitt Performance, São Leopoldo/RS, Brasil.

${ }^{4}$ Doutor em Engenharia Civil, Pesquisador da Universidade do Vale do Rio dos Sinos - UNISINOS- itt Performance, São Leopoldo/RS, Brasil.

${ }^{5}$ Doutora em Engenharia Civil, Professora e Pesquisadora da Universidade do Vale do Rio dos Sinos - UNISINOSCoordenadora geral do itt Performance, São Leopoldo/RS, Brasil.
}

\begin{abstract}
RESUMO
Durante o desenvolvimento das civilizações uma série de construções foram constituídas a partir de rochas. Atualmente, muitas delas se tornaram patrimônios históricos e culturais. Com a homologação da norma de desempenho, NBR 15575 (ABNT, 2013), foi possível identificar entre os profissionais do setor da construção civil a importância de se considerar o desempenho térmico das edificações, entre outros, objetivando melhorar o conforto do usuário. Assim, este artigo busca analisar e comparar a resistência, transmitância e capacidade térmica de sistemas de vedação vertical em rochas, e verificar o atendimento dos requisitos de desempenho térmico conforme NBR 15575-4 (ABNT, 2013) para as zonas bioclimáticas do sul do Brasil. Os resultados deste trabalho mostram que as propriedades térmicas dos rochas mudam não só em função da espessura do elementos, mas também em relação à densidade do material, que culmina na diferenciação do tipo de rocha. Este artigo contribuiu para incrementar o conhecimento sobre o desempenho térmico que cada rocha proporciona em um sistema de vedação e assim o bem estar dos usuários com relação ao conforto térmico das edificações.
\end{abstract}

Palavras-chave: desempenho térmico; rochas; sistema de vedação; patrimônios históricos e culturais.

\section{INTRODUÇÃO}

Durante anos, a pedra natural foi um dos principais materiais utilizados na construção civil, por apresentar grande durabilidade e ser encontrada em abundância (BRITO; FLORES, 2003). A rocha 
sempre esteve presente na vida humana, desde ferramentas para serem usadas como lanças como em construções (ANTUNES LANZER, 2005). Passados os anos, segundo Brito e Flores (2003) muitas construções foram produzidas com rochas e perduram até hoje, como a Pirâmide de Gizé, a Grande Muralha da China e a Torre de Belém. Hoje, elas são atrações turísticas e patrimônios histórico-culturais.

Antunes e Lanzer (2005) destacam que a rocha basalto é abundante em toda a região nordeste do Rio Grande do Sul (RS), por este motivo, foi utilizada em diversas construções locais. Já no Nordeste do Brasil, a alvenaria feita com rocha calcária foi bastante utilizada no litoral paraibano quando os Portugueses chegaram, na realização de igrejas fortificações e outras construções coloniais por ser um material local da região (MOURA, 2013).

No passado, a escolha do artefato para confecção de paredes, se justificava pela sua durabilidade e permitia que os porões mantivessem as condições ideais de umidade e temperatura para a conservação dos alimentos (POSENATO, 1983). Anos passaram, e desenvolveram outros materiais mais leves e industrializados, que substituíram as rochas na construção de alvenarias, como blocos cerâmicos e de concreto. Brito e Flores (2003) explicam que as alvenarias com rocha hoje em dia são raras, devido ao elevado custo e à falta de mão-de-obra especializada neste tipo de construção. Ferreira et al (2017) destacam que o uso desse tipo de construção era predominante em zonas rurais, provavelmente em decorrência da dificuldade de outros insumos em tais regiões.

No entanto, ainda existem muitas construções de alvenaria com rocha, as quais pertencem a um patrimônio histórico, cultural e arquitetônico da região. É necessário analisar as condições dessas edificações e suas características de conforto. (MOURA, 2013). Percebe-se nacionalmente lacunas nessa área de investigação.

De modo complementar, é pertinente destacar que o fraco desempenho térmico das edificações é um dos responsáveis por uma série de danos patológicos à edificação e ao usuário, tais como a condensação, formação de bolor e presença de fungos, eficiência energética, entre outros (SILVA; ROTTA; GARCIA, 2020). É um problema não visível das edificações, mas é perceptível pelos usuários das edificações. O desempenho térmico de sistemas de vedações verticais pode ser analisado segundo a NBR 15575-4 (ABNT-2013) com características dos materiais, cálculos e simulação computacional.

Assim, esse estudo tem como objetivo analisar e comparar a resistência, transmitância e capacidade térmica de sistemas de vedações vertical feitas com diferentes rochas e espessuras, além de avaliar se atendem os parâmetros mínimos e máximos de desempenho térmico da NBR 155754 (ABNT, 2013) para as regiões bioclimáticas do sul do Brasil.

\section{REFERENCIAL TEÓRICO}

\subsection{Alvenaria}

Segundo Caporrino (2018) o sistema de alvenaria de vedação vertical é o mais empregado nas construções do Brasil e no mundo com a função de dividir ambientes internos e externos. O motivo da sua ampla utilização é atribuído principalmente pelo baixo custo e à facilidade de execução quando comparada com outros sistemas. Brito e Flores (2005) explicam que alvenaria constitui de um conjunto de elementos de pequena dimensão, como pedras, tijolos ou blocos, sobrepostos e arrumados, ligados ou não por argamassa, compondo paredes, pontes, fundações ou muros, quando ela resiste a cargas da construção, denomina-se por alvenaria estrutural.

Conforme Silva e Moreira (2017) a vedação vertical, é constituída por paredes, esquadrias e revestimentos e é entendida como um subsistema do edifício que tem como função proteger a edificação contra a ação de agentes indesejáveis como intempéries, animais, ruído e poeira, ela define os ambientes internos e devem também oferecer segurança estrutural, estanqueidade, resistência ao fogo, isolamento térmico, isolamento acústico e durabilidade. 
A função das alvenarias depende de sua localização, interna ou externa (FERREIRA, 2003). As vedações verticais exteriores têm como principal finalidade proteger o interior da construção dos agentes atmosféricos, como água da chuva e vento, a fim de proporcionar estanqueidade do interior. Também, tem como função garantir o isolamento térmico e acústico. (FERREIRA, 2003). Ainda, Ferreira (2003) cita que as construções até o início do século XX continham paredes exteriores com espessura de, aproximadamente, $65 \mathrm{~cm}$ e elevado peso próprio, contudo, apresentavam um comportamento deficiente no que concerne a solicitações horizontais.

Conforme Pinho (2011) como características específicas, estas paredes apresentam, de uma forma geral, uma espessura excessiva e são constituídas por materiais heterogéneos, formando elementos rígidos e pesados, com boa resistência à compressão, menor resistência ao corte e baixa resistência à flexão e tração, excetuando, neste último caso, as paredes exteriores de edifícios com andares altos.

As alvenarias em rocha, de acordo com Brito e Flores (2003) são classificadas conforme o uso da argamassa, são elas: seca, que dispensa a utilização da argamassa; e ordinária, que é constituída por rochas de formas irregulares e diversas dimensões. Ferreira et al (2017) pontuam que o uso de ligantes era uma opção na formação de tais sistemas de parede. Para compreender os requisitos que as paredes de alvenaria em rocha devem atender, é preciso entender a origem das rochas e suas propriedades químicas e físicas.

\subsection{Rochas}

As rochas são resultado de processos naturais como vulcões, terremotos, inundações, geleiras, entre outros, que ocorreram ao longo do tempo (ANTUNES; LANZER 2005). Conforme Moreira (2009), são agregados compostos por um ou mais minerais que representam parte da crosta terrestre e pode ser nitidamente individualizado. As pedras são rochas no estado sólido natural e com dimensões macroscópicas, o petróleo e a areia são algumas rochas que não são consideradas como pedras (MOREIRA, 2009).

As rochas utilizadas na construção de alvenaria podem apresentar naturezas distintas, elas podem ser classificadas como ígneas, sedimentares e metamórficas, de acordo com o seu processo de formação geológica, como explica Martinho (2013). Ainda segundo o autor, as rochas ígneas intrusivas são de granulação grossa, pois o resfriamento lento proporciona que os cristais cresçam lentamente, e constituiu uma das pedras mais comuns na construção civil, tais como o granito. As rochas ígneas extrusivas, possuem granulação fina, pois o rápido esfriamento faz com que os cristais não se desenvolvam bem, e tem-se como exemplo o basalto, também de relevante uso (MARTINHO, 2013). Segundo Moreira (2009) as propriedades mecânicas das rochas metamórficas variam de acordo com o nível de xistosidade (ausente, fraca ou forte), composição mineralógica e textura.

\subsubsection{Classificação das Rochas}

Allen e Iano (2009) citam que a ASTM C 119 classifica a pedra utilizada na construção em seis grupos: granito, calcário, pedras a base de quartzo, ardósia, mármore e outros.

De acordo com Cafezeiro (2016) os granitos são rochas ígneas, de estrutura granular compacta e cristais de grandes dimensões. Segundo Luz e Coelho (2005) consistem principalmente em quartzo, mica e feldspato. Ela possui uma porosidade geralmente muito baixa, além disso, é considerado uma pedra sólida forte e durável, resistentes às intempéries (ALLEN; IANO, 2009). Possui diversas cores, do mais claro ao mais escuro, podendo ser branco, amarelo, verde, marrom, azul, cinza, vermelho e preto. (REDAÇÃO, 2020). O basalto, assim como o granito, é classificado como uma rocha magmática bastante densa e durável (ALLEN; IANO, 2009). Esta rocha é encontrada coloração acinzentado escuro, classificando-se como máfica (cores escuras) (FERREIRA, 2018a). 
Conforme Allen e Iano 2009, o calcário é um dos dois principais tipos de rocha sedimentares aplicado na construção civil. Encontra-se em forma altamente estratificada e ou em depósitos que apresentam pouca estratificação (arenito) (ALLEN; IANO, 2009). De acordo com Sampaio e Almeida (2005) a calcita $\left(\mathrm{CaCO}_{3}\right)$ é o principal componente dos calcários e mármores com alta pureza. Cafezeiro (2016) cita que os calcários possuem elevada porosidade e pouca resistência aos agentes atmosféricos, sendo sucessível a danos por congelamento. Alguns calcários densos podem ser polidos, deste modo são classificados como mármores, mas a maioria é classificado com vários graus de textura superficial (ALLEN; IANO, 2009). A coloração das rochas calcárias pode alternar entre branca, cinza, preto, vermelho, amarelo, azul e verde (FERREIRA, 2018b)

De acordo com Allen e Iano (2009), o arenito é o segundo tipo de rocha sedimentar mais usado na construção civil. Apresentam, em suas generalidades, quartzo, sílica, mica e feldspato como minerais fundamentais, variando em razão das rochas mães que deram origem ao material lítico (CAFEZEIRO, 2016). Os arenitos possuem variações de cores de acordo com a formação e os materiais cimentantes, sendo essas cores cinza, amarela, branca e vermelha (FERREIRA, 2018c).

Conforme Rodrigues (2016), a ardósia é uma pedra metamórfica também utilizada na construção civil, composta de argila ou cinzas vulcânicas. É densa e dura, sendo fácil separá-la em lâminas, útil para pavimentações, telhas e finos revestimentos de parede (ALLEN; IANO, 2009). Rodrigues (2016) explica que a dureza é média, possui baixa porosidade, alta resistência mecânica, alto nível de absorção d'água e alta resistência à ácidos, sendo uma opção para revestir pavimentos, paredes, fachadas, tampos de mesas e outros objetos de decoração, tanto de uso interno como externo. Sua coloração depende dos seus constituintes mineralógicos, as mais comuns são, cinzenta e preta, dependendo do teor de matéria orgânica transformada em grafita, e verde, com clorita. As menos comuns são vermelha e púrpura, que contêm compostos férricos (BINDA, 2019).

Segundo Dalmas (2019) o mármore é um dos principais grupos de rochas metamórficas, formado a partir de calcário, são macias, pouco abrasivas, e com pouca resistência às intempéries, tem menor porosidade e de absorção de água (DALMAS, 2019). É facilmente esculpido e polido, possuindo uma variedade de cores e texturas. Em termos mecânicos é uma pedra frágil e pouco resistente, por isso, mais suscetível a riscos e lascas (ALLEN; IANO, 2009). Sua cor é comumente branca, no entanto, na região em Caçapava do Sul há variedades de cores desta rocha. (DALMAS apud FABRIS, 2019)

Já o grupo de outras rochas, segundo Allen e Iano (2009), inclui rochas como travertino, uma rocha calcítica (composição química idêntica ao do calcário) relativamente rara. Também são classificados como outros as pedras alabrasto, xisto e a pedra sabão (ALLEN; IANO, 2009). Conforme Silva apud Padula e Costa Neto (2017) o xisto tem coloração acinzentada, cinza-escuro, castanha e negra.

\subsection{Propriedades Termofísicas dos Materiais}

A densidade é uma grandeza estabelecida pela razão entre a massa de uma determinada substância, que, no processamento mineral, pode ser uma amostra de rocha, minério ou mineral, e o seu volume (Atkins e Jones, 2001). Matematicamente, a densidade (d) é a razão entre a massa de uma substância (m) e o seu volume (V) (ATKINS; JONES, 2001).

Uma das principais propriedades termofísicas dos materiais utilizados é a condutividade térmica. Conforme Incropera e Dewitt apud Rosemann (2011) a condutividade térmica ( $\lambda$ ) é a capacidade do material de transportar calor, e corresponde a taxa de calor transferida ao longo da espessura de um material por unidade de diferença de temperatura, e é expressa em W/m.K, no sistema internacional de medidas. Ainda Rosemann (2011) explica que quanto menor a condutividade térmica do material, maior isolamento térmico ele oferece. Complementarmente, materiais com elevado calor específico armazenam altas quantidades de calor, e contribuem para o atraso térmico nos sistemas construtivos. Tanto a condutividade térmica quanto $\mathrm{p}$ calor específico 
dos materiais, são relacionados às suas espessuras e densidades, para que se possa concluir sobre seu desempenho térmico. Sendo assim, a eficiência de uma parede em fornecer isolamento térmico depende da baixa condutividade térmica e da elevada capacidade térmica.

Já a resistência térmica é descrita por Costa (2003) como a propriedade de um sistema ou material suportar a transmissão de calor, e é obtida pelo cociente da espessura pela condutividade térmica. Portanto, quanto menor for a condutividade térmica e maior a espessura do elemento, maior será sua resistência térmica. Conforme a NBR 15220-1 (ABNT, 2005), a resistência térmica total $\left(\mathrm{R}_{\mathrm{T}}\right)$ é a soma do conjunto de resistências térmicas parciais correspondentes às camadas de um elemento ou componente, acrescentando as resistências superficiais interna e externa.

$\mathrm{O}$ cálculo da resistência térmica $\left(\mathrm{R}_{\mathrm{T}}, \mathrm{em} \mathrm{m}^{2} . \mathrm{K} / \mathrm{W}\right)$ é feito de acordo com a NBR 15220-2 (ABNT, 2008), sendo a relação entre sua espessura da camada (e, em m) e condutividade térmica $(\lambda$, em $\mathrm{W} / \mathrm{m} . \mathrm{K})$, expressa na Equação 1 .

$$
\mathrm{RT}=\frac{\mathrm{e}}{\lambda}
$$

A resistência térmica de ambiente a ambiente representa os efeitos das trocas de calor por radiação e convecção entre as superfícies do material e o meio que circunda (OLIVEIRA, 2020). A NBR 15220-2 (ABNT, 2008) expressa a resistência térmica superficial na Equação 2.

$$
\mathrm{RT}=\mathrm{Rse}+\mathrm{RT}+\boldsymbol{R s i}
$$

Onde:

RT - resistência térmica de superfície a superfície em $\left(\left(\mathrm{m}^{2} . \mathrm{K}\right) / \mathrm{W}\right)$;

Rse e Rsi - resistências superficiais externa e interna, respectivamente obtidas na Figura 1 abaixo.

Figura 1 - Resistência térmica superficial interna e externa

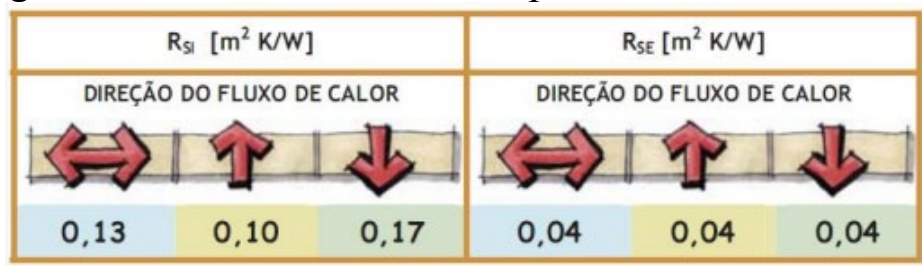

Fonte: Lamberts et. al. (2014) Adaptado da NBR 15220-2 (ABNT, 2008)

A transmitância de calor ou térmica (U) constitui o inverso da resistência térmica de um elemento (MENDONÇA, 2005). A NBR 15220-2 (ABNT, 2008) apresenta a Equação 3 abaixo.

$$
\mathrm{U}=\frac{1}{\mathrm{RT}}
$$

Onde:

$\mathrm{U}$ - transmitância térmica $\left(\mathrm{W} / \mathrm{m}^{2} . \mathrm{K}\right)$;

$\mathrm{R}_{\mathrm{T}}$ - resistência total do elemento $\left(\left(\mathrm{m}^{2} . \mathrm{K}\right) / \mathrm{W}\right)$.

Por fim, a capacidade térmica ou calor específico, segundo Costa (2003), indica a quantidade de calor necessário para variar em $1 \mathrm{~K}$ por $\mathrm{m}^{2}$ sua temperatura. A NBR 15220-2 (ABNT, 2008) informa que a capacidade térmica pode ser determinada pela Equação 4 a seguir.

$$
\mathrm{CT}=\sum_{i=1}^{n} \lambda \mathrm{i} . \text { Ri. ci. } \rho \mathrm{i}=\sum_{i=1}^{n} \text { ei. ci. } \rho \mathrm{i}
$$

Onde:

$\mathrm{C}_{\mathrm{T}}$ - capacidade térmica de um componente em $\left(\mathrm{KJ} /\left(\mathrm{m}^{2} \cdot \mathrm{K}\right)\right)$

$\lambda \mathrm{i}$ - condutividade térmica do material da camada $\mathrm{i}^{\mathrm{a}}(\mathrm{W} /(\mathrm{m} . \mathrm{K}))$;

$\mathrm{Ri}$ - resistência térmica da camada $\mathrm{i}^{\mathrm{a}}\left(\left(\mathrm{m}^{2} . \mathrm{K}\right) / \mathrm{W}\right)$;

ei - espessura da camada em (m);

ci - é o calor específico do material da camada $\mathrm{i}^{\mathrm{a}}(\mathrm{kJ} /(\mathrm{kg} . \mathrm{K}))$; 
pi- é a densidade de massa aparente do material da camada $\mathrm{i}^{\mathrm{a}}$ em $\left(\mathrm{kg} / \mathrm{m}^{3}\right)$.

\section{METODOLOGIA DE PESQUISA}

No Brasil, há lacuna de pesquisas que envolvam a utilização de rochas em vedações verticais e a análise do desempenho nessas construções. Para tal, cabe analisar o tipo de rocha utilizada, para a determinação de indicadores físicos como: densidade; condutividade térmica e calor específico, as quais caracterizam mais profundamente o material e definirá seu desempenho térmico. Duas normas nacionais se aplicam nesse caso: a NBR 15575-4 (ABNT, 2013), referente ao desempenho de sistemas verticais de vedação e a série NBR 15220-1 (ABNT, 2005), 15220-2 (ABNT,2008) e 15220-3 (ABNT,2005) sobre Desempenho Térmico de Edificações.

Desta forma, analisou-se a resistência, transmitância e capacidade térmica das alvenarias feitas com rochas granito, xisto, ardósia, basalto, mármore, calcário e arenito para espessuras de 30, 40, 50, 60 e $65 \mathrm{~cm}$, considerado os cálculos da NBR 15220-2 (ABNT, 2008) mencionados no referencial teórico e verificou se atendem aos requisitos de desempenho térmico sugeridos na NBR 15575-4 (ABNT, 2013). Foram escolhidas essas medidas de espessuras para base de cálculo baseados em artigos e monografias sobre alvenarias de vedação em rocha.

\subsection{Propriedades Térmicas}

A Tabela 1 apresenta a densidade de massa aparente $(\rho)$, condutividade térmica $(\lambda)$ e o calor específico (c) para diferentes rochas segundo a NBR 15220-2 (ABNT, 2008) que será utilizado para o cálculo de resistência térmica e capacidade térmica.

Tabela 1 - Densidade de massa aparente $(\rho)$, condutividade térmica $(\lambda)$ e calor específico (c) dos materiais

\begin{tabular}{|c|l|c|c|c|}
\hline \multicolumn{2}{|c|}{ Material } & $\begin{array}{c}\text { Densidade de Massa } \\
\text { Aparente: } \rho \\
\left(\mathrm{kg} / \mathrm{m}^{3}\right)\end{array}$ & $\begin{array}{c}\text { Condutividade } \\
\text { térmica: } \\
\lambda(\mathrm{W} /(\mathrm{m} . \mathrm{K}))\end{array}$ & $\begin{array}{c}\text { Calor } \\
\text { Específico: c } \\
(\mathrm{kJ} /(\mathrm{kg} . \mathrm{K}))\end{array}$ \\
\hline \multirow{3}{*}{\begin{tabular}{c} 
Pedras (Incluindo $\begin{array}{c}\text { junta de } \\
\text { assentamento) }\end{array}$ \\
\cline { 2 - 5 }
\end{tabular}} & Granito & $2300 \mathrm{a} 2900$ & 3,0 & 0,84 \\
\cline { 2 - 5 } & Xasto, Ardósia & $2000 \mathrm{a} 2800$ & 2,2 & 0,84 \\
\cline { 2 - 5 } & Cármore & 2700 a 3000 & 1,6 & 0,84 \\
\cline { 2 - 5 } & $\geq 2600$ & 2,9 & 0,84 \\
\hline
\end{tabular}

Fonte: Adaptado da NBR 15220-2 (ABNT, 2008).

Segundo Cafezeiro (2016) o arenito, que não é citado na NBR 15220-2 (ABNT, 2008), apresenta um peso específico aparente de aproximadamente $2.651 \mathrm{~kg} / \mathrm{m}^{3}$, sendo considerada uma pedra leve. Sua condutividade térmica é de $3,2 \mathrm{~W} /(\mathrm{m} . \mathrm{K})$ e calor específico é de $0,71 \mathrm{~kJ} /(\mathrm{kg} . \mathrm{K})$ (Buntebarth et al. apud PEREIRA, 2008).

Neste trabalho considerou-se Rsi de $0,13\left(\left(\mathrm{~m}^{2} . \mathrm{K}\right) / \mathrm{W}\right)$ e Rse de $0,04\left(\left(\mathrm{~m}^{2} . \mathrm{K}\right) / \mathrm{W}\right)$, pois representa a direção do fluxo de calor para vedações verticais.

\subsection{Zoneamento Bioclimático Brasileiro}

A NBR 15220-3 (ABNT,2005) indica o zoneamento bioclimático brasileiro, separado em oito zonas. Cada zona possui um conjunto de recomendações técnico-construtivas para o desempenho térmico das edificações. Neste trabalho foram avaliadas as zonas bioclimáticas do Rio Grande do Sul, que correspondem às Z1, Z2 e Z3.

\subsection{Transmitância Térmica}


Os valores máximos de Transmitância Térmica (U) que as paredes externas devem atingir estão apresentadas na Tabela 2 conforme a NBR 15575-4 (ABNT, 2013).

Tabela 2 - Transmitância térmica de paredes externas

\begin{tabular}{|c|c|c|}
\hline \multicolumn{3}{|c|}{ Transmitância Térmica $\mathrm{U}\left(\mathrm{W} / \mathrm{m}^{2} . \mathrm{K}\right)$} \\
\hline Zonas 1 e 2 & \multicolumn{2}{|c|}{ Zonas $3,4,5,6,7$ e 8} \\
\hline \multirow{2}{*}{$\mathrm{U} \leq 2,5$} & $\alpha^{1} \leq 0,6$ & $\alpha^{1}>0,6$ \\
\cline { 2 - 3 } & $\mathrm{U} \leq 3,7$ & $\mathrm{U} \leq 2,5$ \\
\hline 1 & $\alpha$ é absortância à radiação solar da superfície externa da parede. \\
\hline
\end{tabular}

${ }^{1} \alpha$ é absortância à radiação solar da superfície externa da parede.

Fonte: Adaptado da NBR 15575-4 (ABNT, 2013).

\subsection{Capacidade Térmica}

Os valores mínimos que a NBR 15575-4 (ABNT, 2013) recomenda para capacidade térmica (CT) das paredes externas são apresentadas na Tabela 3.

Tabela 3 - Capacidade térmica de paredes externas

\begin{tabular}{|c|c|}
\hline \multicolumn{2}{|c|}{ Capacidade Térmica CT $\left(\mathrm{kJ} / \mathrm{m}^{2} . \mathrm{K}\right)$} \\
\hline Zona 8 & Zonas $1,2,3,4,5,6$ e 7 \\
\hline Sem exigência & $\geq 130$ \\
\hline
\end{tabular}

Fonte: Adaptado da NBR 15575-4 (ABNT, 2013).

\section{RESULTADOS}

Com os dados mencionados, calculou-se a resistência, transmitância e capacidade térmica das rochas granito, xisto, ardósia, basalto, mármore, calcário e arenito para espessuras de 30, 40, 50, 60 e $65 \mathrm{~cm}$ através do cálculo simplificado da NBR 15220-2 (ABNT, 2008). Seguem a seguir os resultados encontrados.

\subsection{Resistência Térmica}

A Tabela 4 apresenta os resultados encontrados de resistência térmica em alvenaria de vedação realizada com diferentes rochas com junta de assentamento.

Tabela 4 - Resistência térmica superficial em Alvenarias de Vedação feitas com diferentes rochas e espessuras

\begin{tabular}{|c|c|c|c|c|c|}
\hline \multicolumn{6}{|c|}{ Resistência Térmica Conforme a NBR 15220-2 (ABNT, 2008) } \\
\hline \multirow[t]{2}{*}{ Rochas } & \multicolumn{5}{|c|}{$\begin{array}{l}\text { Resistência térmica superficial em }\left(\mathrm{m}^{2} \cdot \mathrm{K}\right) / \mathrm{W} \\
\text { para espessuras de: }\end{array}$} \\
\hline & $30 \mathrm{~cm}$ & $40 \mathrm{~cm}$ & $50 \mathrm{~cm}$ & $60 \mathrm{~cm}$ & $65 \mathrm{~cm}$ \\
\hline Granito & 0,27 & 0,30 & 0,34 & 0,37 & 0,39 \\
\hline Xisto e Ardósia & 0,31 & 0,35 & 0,40 & 0,44 & 0,47 \\
\hline Basalto & 0,36 & 0,42 & 0,48 & 0,55 & 0,58 \\
\hline Mármore & 0,27 & 0,31 & 0,34 & 0,38 & 0,39 \\
\hline Calcário & 0,27 & 0,31 & 0,34 & 0,38 & 0,39 \\
\hline Arenito & 0,26 & 0,30 & 0,33 & 0,36 & 0,37 \\
\hline
\end{tabular}

Verifica-se que os valores variam de $0,26\left(\mathrm{~m}^{2} . \mathrm{K}\right) / \mathrm{W}$ utilizando-se o arenito, com $30 \mathrm{~cm}$ de espessura, a $0,58\left(\mathrm{~m}^{2} . \mathrm{K}\right) / \mathrm{W}$ usando-se o basalto, com $65 \mathrm{~cm}$ de espessura. A espessura é proporcional a resistência térmica, já o coeficiente de condutividade térmica é inversamente proporcional a mesma. 
A resistência térmica indica quanto o material vai suportar a passagem de calor na alvenaria de vedação. Desta forma, as alvenarias com basalto são as que maior tem resistência térmica e a rocha de arenito com menor resistência térmica. Observa-se também, que as alvenarias com granito, mármore e calcário possuem os mesmos valores para espessuras de $30,50 \mathrm{e} 65 \mathrm{~cm}$, e variando apenas $0,1\left(\mathrm{~m}^{2} . \mathrm{K}\right) / \mathrm{W}$ do granito para espessuras de 40 e $60 \mathrm{~cm}$.

A NBR 15575-4 (ABNT, 2013) não estipula valores mínimos ou máximos de resistência térmica para alvenarias de vedação, no entanto, a resistência térmica é essencial para o cálculo da transmitância térmica, visto que ela é o inverso da resistência.

\subsection{Transmitância Térmica}

O Gráfico 1 expõem os resultados de transmitância térmica em alvenaria de vedação realizada com diferentes rochas com junta de assentamento considerando a resistência térmica da Tabela 4.

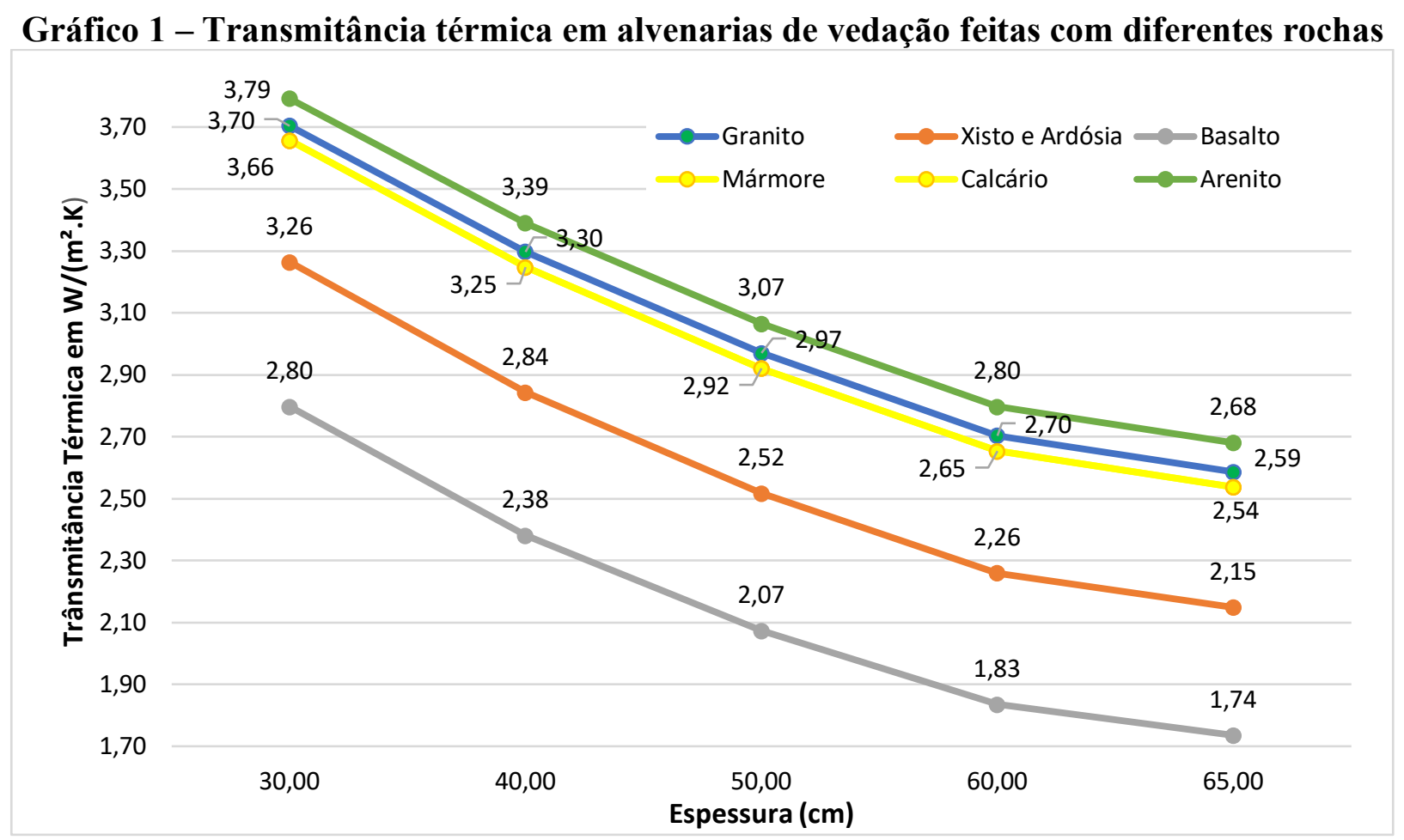

Observa-se que os valores de transmitância térmica (U) variam de $1,74 \mathrm{~W} /\left(\mathrm{m}^{2} . \mathrm{K}\right)$ para o basalto, com $65 \mathrm{~cm}$ de espessura a $3,79 \mathrm{~W} /\left(\mathrm{m}^{2} . \mathrm{K}\right)$ para o arenito, com $30 \mathrm{~cm}$ de espessura. Assim, é visto que quanto maior a espessura e menor a condutividade térmica, menor é o resultado da transmitância térmica.

Conforme a NBR 15575-4 (ABNT, 2013) há requisitos mínimos de transmitância térmica para alvenarias de vedação exteriores, conforme apresentados na Tabela 2. Analisando os valores para a zona Z1 e Z2, ambas devem ser menores ou igual a $2,5 \mathrm{~W} /\left(\mathrm{m}^{2} . \mathrm{K}\right)$.

Desta forma, para estas zonas, analisou-se os valores mínimos para transmitância térmica das alvenarias de vedação em rocha deste estudo, e observou-se os seguintes resultados:

- O basalto, atinge os valores mínimos a partir de $40 \mathrm{~cm}$ de espessura, com 2,38 $\mathrm{W} /\left(\mathrm{m}^{2} . \mathrm{K}\right)$;

- O xisto e ardósia quase atingem os valores mínimos com $50 \mathrm{~cm}$ de espessura, contudo, ficam com $0,2 \mathrm{~W} /\left(\mathrm{m}^{2} . \mathrm{K}\right)$ a mais do que a norma de desempenho estipula. Desta forma, ela começa a atender a partir de $60 \mathrm{~cm}$ de espessura com valor de 2,26 $\mathrm{W} /\left(\mathrm{m}^{2} . \mathrm{K}\right)$; 
- As demais rochas não atendem a norma de desempenho térmico. O mármore, calcário por pouco atingem os valores mínimos para espessuras de $65 \mathrm{~cm}$ de espessura, com $2,54 \mathrm{~W} /\left(\mathrm{m}^{2} . \mathrm{K}\right)$ e após o granito com $2,59 \mathrm{~W} /\left(\mathrm{m}^{2} . \mathrm{K}\right)$ com a mesma espessura. E o arenito é o que tem maiores valores, tendo $2,68 \mathrm{~W} /\left(\mathrm{m}^{2} . \mathrm{K}\right) \mathrm{com} 65 \mathrm{~cm}$ de espessura ficando $0,18 \mathrm{~W} /\left(\mathrm{m}^{2} . \mathrm{K}\right)$ acima do valor mínimo.

Analisando a transmitância térmica de cada sistema para a zona Z3, nota-se que os valores mínimos de transmitância térmica dependem da absortância à radiação solar da superfície externa da parede. Então, como a norma não estipula valores de absortância para rochas, classificou-se a absortância das rochas a partir de suas cores, conforme a NBR 15220-2 (ABNT, 2008).

Observa-se que para cores claras, a absortância tende a ser menor que 0,6 e para cores mais escuras, maiores que 0,6. Então, adotou-se que para atender a norma de desempenho, a 15575-4 (ABNT,2013), na zona Z3, a transmitância térmica, para as rochas claras, devem ser iguais ou menores que $3,7 \mathrm{~W} /\left(\mathrm{m}^{2} . \mathrm{K}\right)$ e para as rochas escuras, iguais ou menores que $2,5 \mathrm{~W} /\left(\mathrm{m}^{2} . \mathrm{K}\right)$. Como o requisito para rochas escuras é igual para zona $\mathrm{Z} 1$ e Z2, adotou-se a mesma análise realizada destas zonas para rochas escuras na zona Z3.

Desta forma avaliou-se as rochas claras, para a zona Z3, que tendem a possuir absortância térmica menor que 0,6, e desta forma, a sua transmitância térmica deve ser igual ou menor que 3,7 $\mathrm{W} /\left(\mathrm{m}^{2} . \mathrm{K}\right)$. Começando a análise pelos valores mínimos de transmitância térmica:

- A rocha basalto, que possui os menores valores de transmitância térmica, é caracterizada pela sua coloração escura, provavelmente sua transmitância é acima de 0,6, assim não se enquadra na análise na zona 3, para absortância menor de 0,6;

- Em seguida, o xisto e a ardósia apresentam algumas colorações claras, o xisto como cores acinzentada e castanha e a ardósia acinzenta e verde clara. Para essas colorações claras, verificou-se que para todas espessuras elas atendem a norma, o valor mais alto é de $3,26 \mathrm{~W} /\left(\mathrm{m}^{2} . \mathrm{K}\right)$, para espessura de $30 \mathrm{~cm}$, sendo aproximadamente 1,13 vezes menor que o limite sugerido, que é $3,7 \mathrm{~W} /\left(\mathrm{m}^{2} . \mathrm{K}\right)$. O menor valor foi de $2,15 \mathrm{~W} /\left(\mathrm{m}^{2} . \mathrm{K}\right)$, tendo uma boa margem até o valor máximo que a norma permite;

- Após o xisto e ardósia, vem o calcário e mármore, os quais possuem os mesmos valores de transmitância térmica e ambos têm variações de cores claras, como branco, amarelo, acinzentado (se aproximando da cor "alumínio") e verde claro. Observa-se que para essas cores, todas espessuras analisadas atendem a norma. $\mathrm{O}$ valor mais alto encontrado foi de $3,66 \mathrm{~W} /\left(\mathrm{m}^{2} . \mathrm{K}\right)$, para espessura de $30 \mathrm{~cm}$, tendo a 0,04 a menos que a norma permite. E o resultado do valor mais baixo de 2,54 $\mathrm{W} /\left(\mathrm{m}^{2} . \mathrm{K}\right)$, sendo aproximadamente $68,6 \%$ do valor máximo;

- A seguir, rocha granito apresenta valores mais altos para transmitância térmica, como ela possui diversas cores, do mais claro ao mais escuro, estabeleceu-se as cores mais claras como branco, amarelo, verde claro e acizentado (esse último por se assemelhar com a cor alumínio). Assim, para essas determinadas cores, avaliouse que para todas as espessuras, os valores atendem a norma, sendo o valor mais alto para $30 \mathrm{~cm}$ de espessura, de $3,7 \mathrm{~W} /\left(\mathrm{m}^{2} . \mathrm{K}\right)$, atingindo o limite que a norma estabelece, e o menor resultado fica em $2,59 \mathrm{~W} /\left(\mathrm{m}^{2} . \mathrm{K}\right)$;

- E por último, o arenito que apresenta cores claras como cinza (se assemelhando a cor "alumínio"), amarelo e branca. Atendem a norma a partir da espessura de $40 \mathrm{~cm}$, com $3,39 \mathrm{~W} /\left(\mathrm{m}^{2} . \mathrm{K}\right)$. A espessura de $30 \mathrm{~cm}$, tem $3,79 \mathrm{~W} /\left(\mathrm{m}^{2} . \mathrm{K}\right)$ ultrapassando em $0,09 \mathrm{~W} /\left(\mathrm{m}^{2} . \mathrm{K}\right)$ exigido pela norma.

\subsection{Capacidade Térmica}


Conforme o cálculo na NBR 15220-2 (ABNT, 2008), o valor estipulado para a capacidade térmica em alvenarias de vedação exteriores deve ser maior ou igual a $130 \mathrm{KJ} /\left(\mathrm{m}^{2} . \mathrm{K}\right)$. Para este cálculo, utilizou-se os dados de calor específico e a menor densidade de massa aparente da Tabela 1, para obter os menores resultados e as diferentes espessuras. A Tabela 5 e o Gráfico 2 expõem os resultados de capacidade térmica em alvenaria de vedação realizada com diferentes rochas, com junta de assentamento.

Tabela 5 - Capacidade térmica em alvenarias de vedação feitas com diferentes rochas e espessuras

\begin{tabular}{|c|c|c|c|c|c|}
\hline \multicolumn{6}{|c|}{ Capacidade Térmica (CT) conforme a NBR 15220-2 (ABNT, 2008) } \\
\hline \multirow{2}{*}{ Rochas } & Capacidade Térmica em $\mathrm{kJ} /\left(\mathrm{m}^{2} . \mathrm{K}\right)$ para espessuras de: \\
\cline { 2 - 6 } & $30 \mathrm{~cm}$ & $40 \mathrm{~cm}$ & $50 \mathrm{~cm}$ & $60 \mathrm{~cm}$ & $65 \mathrm{~cm}$ \\
\hline Granito & 579,60 & 772,80 & 966,00 & 1159,20 & 1255,80 \\
\hline Xisto e Ardósia & 504,00 & 672,00 & 840,00 & 1008,00 & 1092,00 \\
\hline Basalto & 680,40 & 907,20 & 1134,00 & 1360,80 & 1474,20 \\
\hline Mármore & 655,20 & 873,60 & 1092,00 & 1310,40 & 1419,60 \\
\hline Calcário & 655,20 & 873,60 & 1092,00 & 1310,40 & 1419,60 \\
\hline Arenito & 564,66 & 752,88 & 941,11 & 1129,33 & 1223,44 \\
\hline
\end{tabular}

Gráfico 2 - Capacidade térmica em alvenarias de vedação feitas com diferentes rochas e espessuras

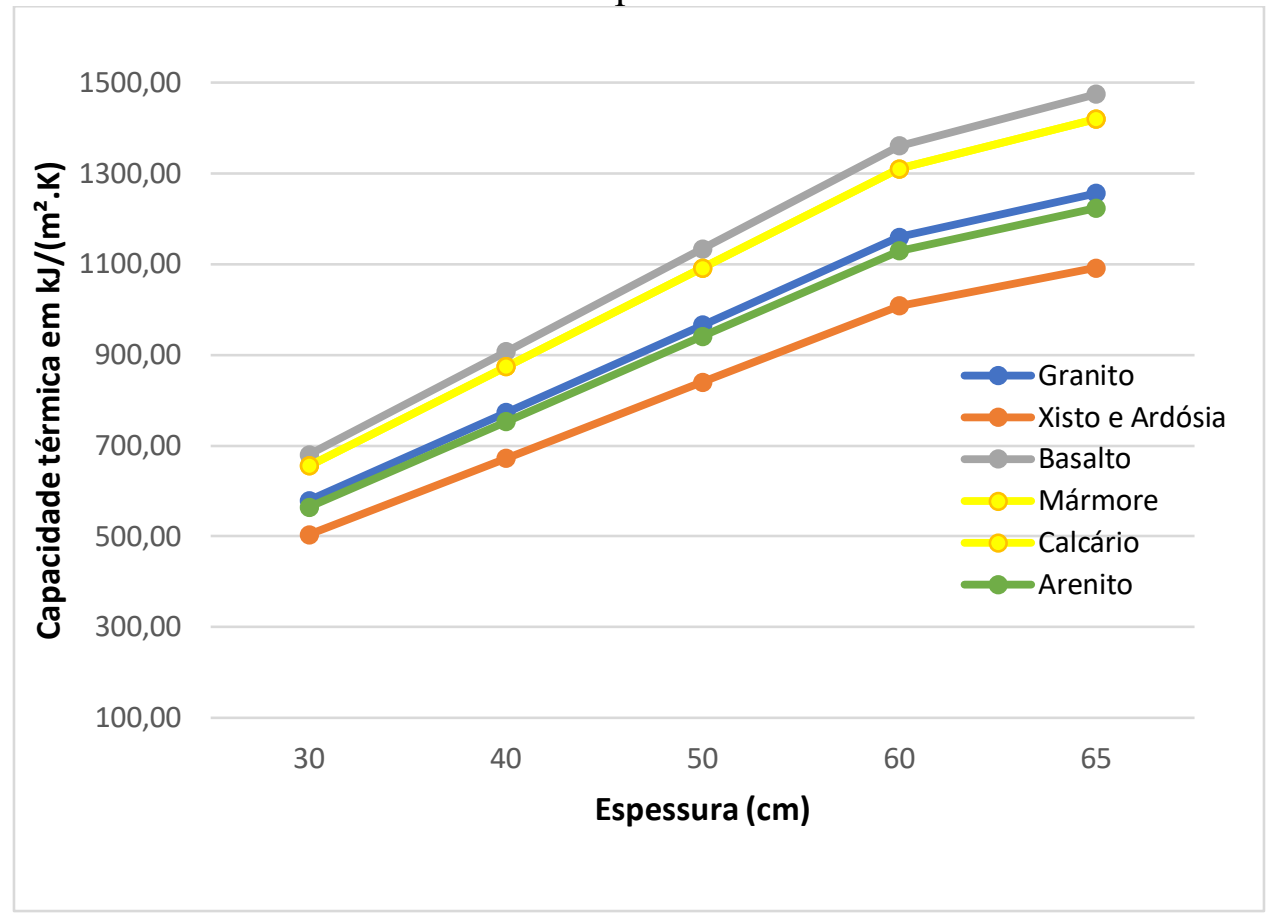

Analisando os resultados, observa-se que para todos diferentes sistemas de vedação em rocha atendem o requisito mínimo da Norma 15575-4 (ABNT, 2013) para capacidade térmica nas Zonas 1,2 e 3 possuindo valores superiores a $130 \mathrm{~kJ} /\left(\mathrm{m}^{2} . \mathrm{K}\right)$. O menor valor é de $504 \mathrm{~kJ} /\left(\mathrm{m}^{2} . \mathrm{K}\right)$ do xisto e ardósia, com $30 \mathrm{~cm}$ de espessura, sendo 3,8 vezes maior que o requisito mínimo da norma de 130 $\mathrm{kJ} /\left(\mathrm{m}^{2} . \mathrm{K}\right)$. Também é visto quanto maior a espessura maior a capacidade térmica. Com isso, todas as rochas analisadas se mostram com uma grande capacidade térmica, precisando de bastante quantidade de calor para variar em $1 \mathrm{~K} / \mathrm{m}^{2}$ sua temperatura, e isso é devido a seu elevado calor 
específico e densidade do elemento, mesmo considerando no cálculo a menor densidade de cada rocha.

Analisando dos maiores aos menores valores, conforme a Tabela 5 e Gráfico 2:

- O sistema que possui maior capacidade térmica é com basalto com 1.474,20 $\mathrm{KJ} /\left(\mathrm{m}^{2} . \mathrm{K}\right)$, com $65 \mathrm{~cm}$ de espessura a $680,40 \mathrm{KJ} /\left(\mathrm{m}^{2} . \mathrm{K}\right)$, com $30 \mathrm{~cm}$ de espessura.

- Após vem os com mármore e calcário, com $1.419,60 \mathrm{KJ} /\left(\mathrm{m}^{2} . \mathrm{K}\right)$, com $65 \mathrm{~cm}$ de espessura a $655,20 \mathrm{KJ} /\left(\mathrm{m}^{2} . \mathrm{K}\right)$, com $30 \mathrm{~cm}$ de espessura.

- O com granito fica no meio-termo entre as rochas analisadas conforme o Grafico 2, tem valores que variam do $1255,80 \mathrm{KJ} /\left(\mathrm{m}^{2} . \mathrm{K}\right)$, com $65 \mathrm{~cm}$ de espessura a 579,60 $\mathrm{KJ} /\left(\mathrm{m}^{2} . \mathrm{K}\right)$, com $30 \mathrm{~cm}$ de espessura.

- Bem próximo aos valores com granito, mas com valores menores, vem o arenito, $1223,44 \mathrm{KJ} /\left(\mathrm{m}^{2} . \mathrm{K}\right)$, com $65 \mathrm{~cm}$ de espessura a $564,66 \mathrm{KJ} /\left(\mathrm{m}^{2} . \mathrm{K}\right)$, com $30 \mathrm{~cm}$ de espessura.

- E por último, os sistemas que possuem os menores valores, mas ainda tem uma ótima capacidade térmica, o xisto e ardósia $1092,00 \mathrm{~kJ} /\left(\mathrm{m}^{2} . \mathrm{K}\right)$, com $65 \mathrm{~cm}$ de espessura a $504,00 \mathrm{KJ} /\left(\mathrm{m}^{2} . \mathrm{K}\right)$, com $30 \mathrm{~cm}$ de espessura.

\section{CONCLUSÃO}

A maioria das construções com rochas trazem um grande valor arquitetônico e cultural para as cidades. Assim, analisou-se e comparou-se a resistência, transmitância e capacidade térmica de sistemas de vedações verticais feitas com diferentes rochas e espessuras e em paralelo verificou-se se atendem os parâmetros mínimos e máximos de desempenho térmico as quais constam na norma de desempenho NBR 15575-4 (ABNT, 2013). Assim, foi possível inferir que para cada rocha e espessura utilizada em um sistema de vedação, os valores divergem para resistências, transmitâncias e capacidades térmica devem ser levadas em consideração para avaliação deste desempenho térmico.

Os sistemas de vedação em basalto se destacaram por apesentarem os menores valores de transmitância térmica e maiores de capacidade térmica, entretanto, os em arenito apresentaram os maiores resultados de transmitância térmica e menores de capacidade térmica, com uma grande variação entre as duas. Assim, para transmitância térmica, foi visto que para as zonas 1, 2 e 3 (este último, para rochas consideradas escuras, com absortância maior que 0,6 ) os com basalto atingem os requisitos mínimos a partir de $40 \mathrm{~cm}$ de espessura, com $2,38 \mathrm{~W} /\left(\mathrm{m}^{2} . \mathrm{K}\right)$, os com xisto e ardósia atendem a norma somente com $60 \mathrm{~cm}$ de espessura com valor de $2,26 \mathrm{~W} /\left(\mathrm{m}^{2} . \mathrm{K}\right)$ e com as demais rochas, infelizmente, não atendem a norma, nas espessuras analisadas, apresentado valores superiores a 2,5 W/( $\left.\mathrm{m}^{2} . \mathrm{K}\right)$. Com isso, pode-se observar que a maioria dos sistemas com rochas utilizadas não atendem os parâmetros mínimos de transmitância térmica, precisando de cuidado na decisão de qual rocha e espessura escolher no caso da realização de novas construções.

Para a zona 3, as requisitos para transmitância térmica mudam para as rochas que possuem cores claras, as quais provavelmente possuem absotância menores ou iguais a 0,6 , devem ter resultados de transmitância térmica menores ou iguais a $3,7 \mathrm{~W} /\left(\mathrm{m}^{2} . \mathrm{K}\right)$. Desta forma, os sistemas de vedações com o xisto, ardósia, calcário, mármore e granito, com cores claras, para todas as espessuras analisadas atendem a norma, sendo menores ou iguais a $3,7 \mathrm{~W} /\left(\mathrm{m}^{2} . \mathrm{K}\right)$. Já com arenito, de cores claras, começa a atender a norma com $40 \mathrm{~cm}$, com 3,39 W/(m².K). Como o basalto não possui cor clara, não se enquadra neste requisito desta zona para absortância menores ou iguais a 0,6. Assim para esta zona e absortância, fica mais evidente que se a maioria das rochas e espessuras atingem os requisitos mínimos para vedações verticais externas por este ser maior que das outras zonas. 
Já a capacidade térmica para os sistemas de vedações em rochas analisados, todos possuem uma ótima capacidade térmica e isto se deve, principalmente pela a alta densidade de massa aparente das rochas. Assim, todos os sistemas analisados atendem o requisito mínimo da norma de desempenho para paredes de alvenaria exteriores, ficando além do mínimo sugerido.

Desta forma, o estudo ajudará e facilitará os arquitetos e engenheiros a determinem, de forma correta, quais rochas e espessuras proporcionam um bom desempenho térmico a se utilizar em um sistema de vedação vertical, além disso quais estarão de acordo com a norma de desempenho térmico.

Por fim, o trabalho proporcionou o conhecimento do desempenho térmico de alvenarias de vedações em rocha, na qual ajudará nos estudos das construções feitas com rochas, as quais no Brasil são poucos, valorizando assim essas construções que a maioria são patrimônios históricos e culturais.

\section{REFERENCIAS BIBLIOGRÁFICAS}

Associação Brasileira de Normas Técnicas. NBR 15220-1: Desempenho térmico de edificações - Parte 1: Definições, símbolos e unidades. Rio de Janeiro, 2005.

NBR 15220-2: Desempenho térmico de edificações - Parte 2: Método de cálculo da transmitância térmica, da capacidade térmica, do atraso térmico e do fator solar de elementos e componentes de edificações. Rio de Janeiro, 2008.

.NBR 15220-3. Desempenho térmico de edificações - Parte 3: Zoneamento bioclimático brasileiro e diretrizes construtivas para habitações unifamiliares de interesse social. Rio de Janeiro. 2005.

. NBR 15575-1: Edificações habitacionais - Desempenho - Parte 1: Requisitos gerais. Rio de Janeiro, 2013.

. NBR 15575-4: Edificações habitacionais — Desempenho - Parte 4: Requisitos para os sistemas de vedações verticais internas e externas — SVVIE. Rio de Janeiro, 2013.

ALLEN, EDWARD; IANO, JOSEPH. Fundamentos da engenharia e edificações: materiais e métodos. 5 ed. Porto Alegre: Bookman, 2009. P.989.

ANTUNES, Janete Rotta; LANZER, Rosane Maria. A pedra basalto como atrativo turístico em roteiros- temáticos para a região uva e vinho. Turismo em Análise, v. 16, n. 2, p.174-190. Caxias do Sul, 2005.

ATKINS, P; JONES, L. Princípios de química: questionando a vida moderna e o meio ambiente. Porto Alegre: Bookman, 2001, p.39-40.

BINDA, Felipe Ferreira. Preparo e caracterização de elementos de fricção à base de resina fenólica e pó de ardósia. Rede Temática Em Engenharia De Materiais - REDEMAT. Dissertação de Mestrado. Minas Gerais: Ouro Preto: 2019.

BRITO, JORGE.; FLORES, INÊS. Paredes de alvenaria de pedra natural. Instituto Superior Técnico, Mestrado Avançado em Construção e Reabilitação, Cadeira de Construção de Edifícios. Lisboa, 2003. 
CAETANO, DANIEL JORGE. Minerais e rochas: rochas metamórficas e o ciclo das rochas. Geologia para Engenharia Civil. São Paulo, 2012.

CAFEZEIRO, YAN GRACO DANTAS. Os muros antigos e as contribuições dos métodos de diagnóstico pouco ou não destrutivo para avaliação física e mecânica. Universidade Federal Da Bahia. Faculdade De Arquitetura. Programa De Pós-Graduação Em Arquitetura E Urbanismo. Salvador, 2016.

CAPORRINO, CRISTINA FURLAN. Patologias em alvenarias. 2. Ed. São Paulo:Oficina de Textos, 2018.

COSTA, Ennio Cruz. Física aplicada à construção: conforto térmico. $4^{\circ} \mathrm{ed}$. São Paulo, 2003.

DALMAS, Andreas Glass. Caracterização tecnológica com ênfase no ataque químico em mármore para uso ornamental. Universidade Federal do Pampa. Trabalho de Conclusão de Curso II. Caçapava do Sul: 2019.

FERREIRA, Ana Luísa. Causas e classificações de patologias em paredes de alvenaria de pedra. Monografia realizada na cadeira de Tecnologia de Construção de Edificios do Mestrado em Construção, Construlink Press, Oeiras, 2003.

FERREIRA, Letícia. Rochas: arenito. Geoportal - UFJF. 2018c.

FERREIRA, Letícia. Rochas: basalto. Geoportal - UFJF. 2018a.

FERREIRA, Letícia. Rochas: calcárias. Geoportal - UFJF. 2018 b.

FLORES, Inês; BRITO, Jorge. Patologia e reabilitação de contrução e alvenaria de pedra. Apontamentos da cadeira de reabilitação de edifícios. Licenciatura em Arquitectura. Instituto superior técnico. Lisboa, 2005.

LAMBERTS, Roberto; DUTRA, Luciano; PEREIRA, Fernando O. R. Eficiência Energética na Arquitetura. $3^{\text {a }}$ edição. Rio de Janeiro: ELETROBRAS/PROCEL, 2014.

LUZ; Adão Benvindo; COELHO, José Mario. Feldspato. Rochas e Minerais Industriais $\mathrm{CETEM} / 2005$.

MANUEL, Fernández Cánovas. Patologia e terapia do concreto armado. Coordenação técnica L.A. Falcão Bauer; 'tradução de M. Celeste Marcondes, Calos Wagner Fernandes dos Santos, Beatriz Cannabrava'. São Paulo: Pini, 1988.

MARTINHO, Caroline Thais. Minerais e Rocha: Constituintes da Terra Sólida. Pontifícia Universidade Católica do Rio Grande do Sul. Faculdade de Engenharia. Geologia Aplicada. Porto Alegre, 2013.

MENDONÇA, Paulo. Habitar sob uma segunda pele: estratégias para a redução do impacto ambiental de contruções solares passivas em climas temperados. Anexo 1 Propriedades dos Materiais e Sistemas de Fachada. Tese de doutorado. Universidade do Minho. Portugal, 2005. 
MOREIRA, Anabela Mendas. Pedras naturais. Departamento de Engenharia Civil Área de Construção. Materiais de Construção I - $1^{\circ}$ Semestre. Instituto Politécnico de Tomar. Escola Superior de Tecnologia de Tomar. Tomar, Portugal, 2009.

MOURA, Paulo Germano Toscano. Reabilitação com argamassa projetada em construções históricas de pedra no litoral paraibano. Tese submetida ao Programa de PósGraduação em Arquitetura e Urbanismo do Doutorado Interinstitucional - DINTER promovido pelas Universidades Federal da Bahia - UFBA e Federal da Paraíba, Salvador, 2013. p.160.

OLIVEIRA, Maria Fernanda. Desempenho térmico. Desempenho acústico, térmico e lumínico das edificações. Especialização em Patologia e Desempenho das Construções. UNIVERSIDADE DO VALE DO RIO DOS SINOS - UNISINOS. Rio Grande do Sul, Porto Alegre: 2020.

PEREIRA, Emmanoelle Santos. Determinação das propriedades térmicas das rochas do embasamento adjacente a bacia do recôncavo. Universidade Federal da Bahia, Instituto de Geociências, Curso De Graduação em Geofísica. GEO213 - Trabalho de Graduação. Bahia: Salvador, 2008.

PINHO, Fernando. Aspetos construtivos e funcionais das paredes divisórias na construção tradicional. In LOURENÇO, Paulo; et al. - Paredes Divisórias: Passado, presente e futuro. Porto: Ed. Universidade do Minho, junho 2011.

POSENATO, J. Arquitetura da imigração italiana do Rio Grande do Sul: assim vivem os italianos. Porto Alegre, 1983.

REDAÇÃO. Tipos de granito: veja fotos com cores, exemplos e outras dicas. Decorfácil.13/03/2020. https://www.decorfacil.com/tipos-de-granito/ (data da consulta 05/10/2020).

ROCHA, Manuel. Propriedades índice e classificação das rochas. In mecânica das rochas. Lisboa: LENEC, 1981. https://paginas.fe.up.pt/ geng/ge/apontamentos/Cap_3_GE.pdf (data da consulta 24/07/2020).

RODRIGUES, Elyzia. Ardósia: durabilidade, versatilidade e preço baixo. Blog Dica da Arquiteta. 2016. http://www.dicadaarquiteta.com.br/2016/01/ardosia-durabilidade-versatilidadee.html.aCESSADO (data da consulta 06/06/2020).

ROSEMANN, Fernando. Resistência ao fogo de paredes de alvenaria estrutural de blocos cerâmicos pelo critério de isolamento térmico. Universidade Federal de Santa Catarina. Centro Tecnológico Programa de Pós-Graduação em Engenharia Civil. Florianópolis: 2011.

SAMPAIO, João Alves; ALMEIDA, Salvador Luiz Matos. Calcário e Dolomito. Rochas e Minerais Industriais. CETEM, 2005.

SILVA, Cleriston Ferreira. Condutividade térmica, difusividade térmica e calor específico em rochas ígneas e metamórficas: comportamento isotrópico e anisotrópico. Universidade Federal da Bahia, Instituto de Geociências, Curso de Graduação em Geofísica. GEO213 - Trabalho de Graduação. Bahia: Salvador, 2010. 
SILVA, Filipe Manuel Fernandes. Estudo de materiais de isolamento térmico inovadores. Dissertação submetida para satisfação parcial dos requisitos do grau de MESTRE EM ENGENHARIA CIVIL- ESPECIALIZAÇÃO EM CONSTRUÇÕES CIVIS. Faculdade de Engenharia. FEUP Universidade do Porto, 2013.

SILVA, Maria de Fatima Dantas. Pigmentos a base de xisto retortado impregnado com metais para aplicação em esmaltes cerâmicos. Universidade Federal do Rio Grande do Norte. Centro de Ciências Exatas e da Terra, Programa de Pós Graduação em Ciência e Engenharia de Materiais. Tese Doutorado. Rio Grande Do Norte: Natal, 2017.

SILVA, Patrícia Emília Villela; MOREIRA, Rodrigo Resende. Projeto de alvenaria de vedação - diretrizes para a elaboração, histórico, dificuldades e vantagens da implementação e relação com a nbr 15575. Monografia. Trabalho de Conclusão de Curso II do Curso de Graduação de Engenharia Civil da Universidade Federal de Goiás. Goiana, 2017. P 79.

Silva, Jonas Cegelka; Rotta, Renata; Garcia, Isabel Krey. Avaliação da prendizagem em uma prova interdisciplinar sobre física térmica. Revista Areté, v. 13 n. 27. 2020.

FERREIRA, J.A.; FREITAS, M.; MATOS, M.X.G.de; MAIOR, P.M.S. Além da Pedra: Utilização de Rochas em Alvenarias nas Zonas Rurais no Nordeste do Brasil, Séculos XVII ao XX. Fumdhamentos (2017), vol. XIX. PP. 12-43. 